\title{
天山乌鲁木齐河源区石冰川的 温度结构类型与运动机制
}

\author{
崔之久** 朱 诚
}

(北京大学地理系)

关调词石堆、倒石堆前缘堤、大陆性冷底石冰川、海洋性暖底石冰川

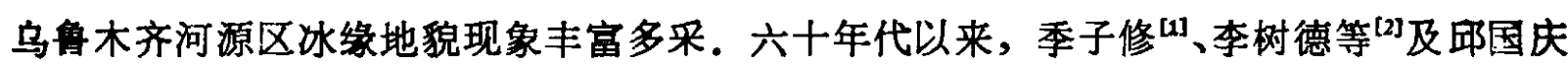
等***曾对本区岩石风化、石环、石河、拔石、冻胀丘等做过初步的解剖分析，积累了宝贵资料. 但前人对石冰川几乎未涉及，1985-1987 年，作者对本区石冰川进行了较系统的定位观测和 研究, 得出以下主要结果.

\section{一、形态和分布}

本区石冰川有十数条，几乎全部由倒石堆或倒石堆前缘堤演化而来,按一般成因划分属倒 石堆型石冰川(如 RG3、RG4、RG5) 或倒石堆前缘堤型石冰川(如 RG2), 按作者之一的石 冰川分类则多属于科罗拉多型 ${ }^{[3]}$ (意即由倒石堆演变而来).

本区石冰川可单独或成群出现, 单独出现的石冰川具有下述特点: (1) 一般长 $30-60 \mathrm{~m}$, 宽 $100-150 \mathrm{~m}$, 前缘高 $20-41) \mathrm{m}$; (2) 前缘坡度较大 $\left(30^{\circ}-41^{\circ}-60^{\circ}\right)$, 从顶到前缘坡有一明 显坡折; (3) 有的石冰川坡脚延伸出一个因挤压而成的兔占平台或顶部出现槽和脊. 这些特 征形态是原始倒石堆所不应具有的.

倒石堆直接演变的石冰川和倒石堆前缘堤型石冰川有一定区别：前者的形成是由于本区 倒石堆大多集中于阴坡坡簏, 雨水、融雪水渗入倒石堆后受低温影响不易融化, 加之地形、坡 度等影响便使倒石堆具有向前螦动的特性，蠕动过程长期进行便演化为维型石冰川，并进一 步转化为目前所见的叶状石冰川。倒石堆前缘堤型石冰川的形成, 首先是由沿倒石堆前缘呈 弧线状延伸的堤状堆积体 (即倒石堆前缘堤). 由于雪融水和雨水的流人以及重新冻结, 此 堤内常有冰岩混合体, 易产生蟙动现象。予! 且其后侧倒石堆规模亦在不断扩大，随时间推移， 两者连成一体便形成典型的叶状或舌状石冰川（如图 1)。此类石冰川以其前缘文倾坡 ( $8^{\circ}$ $17^{\circ}$ )为特点. 与倒石堆型石冰川明显有别 (思 2 ).

瑞士 W. Haeberli 曾根据阿尔卑斯山的状况提出了石弥川的理论分布模式 ${ }^{[4]}$. 他认为 石冰川多在冻土下界以上和冰川零平衡线以下之间的地带内发育．任乌鲁木齐河源区，冰川 零平衡线约 $4050 \mathrm{~m}$, 多年冻土下界为 $3200 \mathrm{~m}$, 而石冰川分布上界约 $3900 \mathrm{~m}$, 与 Haeberli 分布

本文 1987 年9月17日收到。1988 年7月4日收到售改模.

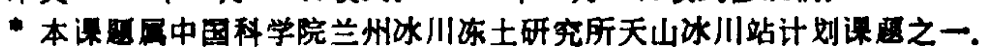

**为中国科学院兰州冰川胨土研究所兼职研究员.

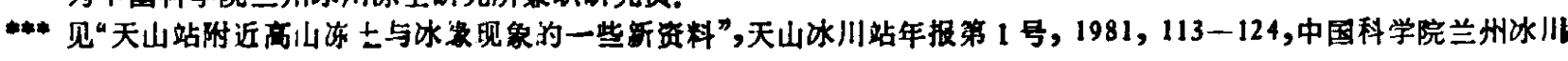
冻: 上研究所编。 


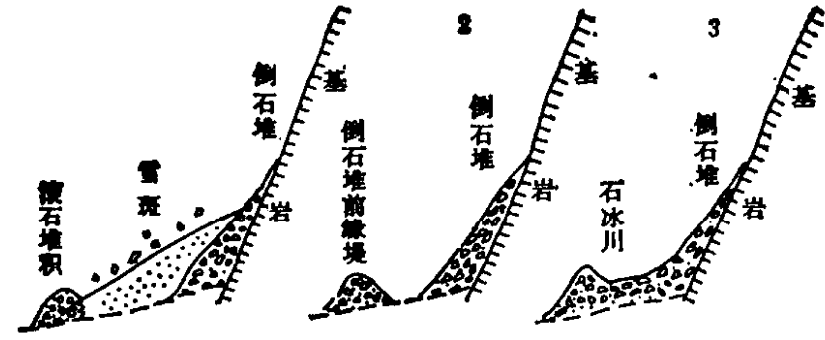

图 1 倒石堆前缘堤的形成及其向石冰川的 转化(按 $1-3$ 顼序)

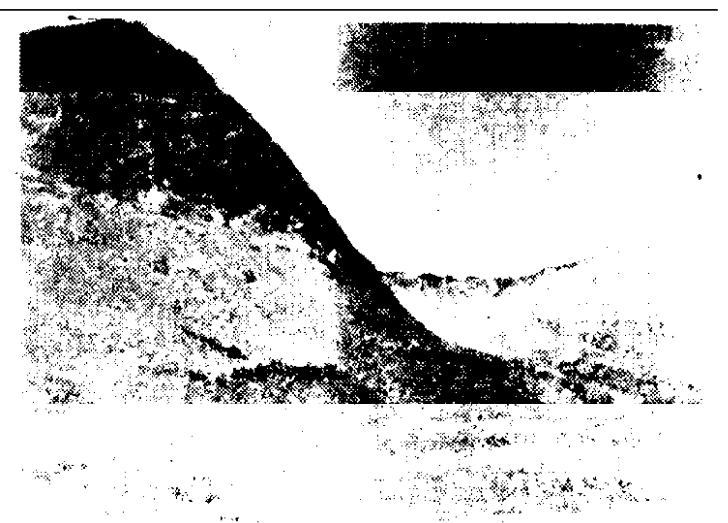

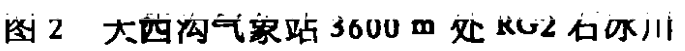
全贯(箭头所示)

模式大体相同.

\section{二、结 构 模 式}

1. 坑探资料我们曾于 1986 年 6-7 月两次在 RG3 和 RG5 石冰川顶部不同部位进 行爆破坑探，6月底在 RG3 石冰川表面以下 $1.31 \mathrm{~m}$ 处发现 $20 \times 15 \times 8 \mathrm{~cm}$ 规模的冰透镜 体,冰体洁净, 其四周为片麻岩块, 岩块间有细粒岩屑充填. 在 RG5 石冰川表面以下 $0.8 \mathrm{~m}$ 深 处见含粒状冰的冻结角砾土、在 $1.2 \mathrm{~m}$ 深处见含孔隙冰的冻结岩屑, 在其细粒物质间有多层厚 度为 $1-3 \mathrm{~mm}$ 的层状冰. 7 月底的爆破发现与上述有类似特征, 只是深度有所加大.

由坑探得知: 本区石冰川中有一活动层和冻结层, 其活动层 7 月底深度范围 在 $1.43-$ $1.9 \mathrm{~m}$ 之间; 其冻结层由含冰透镜体和孔隙冰的冻结岩屑体组成. 这些均为冰胶结型石冰川的 典型特征.

2. 物探资料用 DDC-2A 型电子自动补偿仪对本区石冰川进行电测深 ${ }^{1)}$, 发现该区石 冰川可分为三层结构. 第一层为活动层, 电阻率 $25000 \mathrm{~m}$, 厚度 $1.5 \mathrm{~m}$ (由二层量板确定); 第二 层根据坑探资料分析应属于冻结砂砾石层, 由于含冰故电阻率增至 $3.7 \times 10^{4} . Q \mathrm{~m}$; 在 $A B / 2$ 为 $110 \mathrm{~m}$ 处电阻率逐渐降至 $3.2 \times 10^{4} \Omega_{\mathrm{m}}$, 由于此处深度仅为百余米, 且电阻率虽有下降但仍比 未冻结沉积物具有的电阻率 $0.5-5 \times 10^{3} \mathrm{Om}$ 更高一个数量级. 由此推测此层应为电阻率比含 冰冻结砂砾石低的基岩 (电测处表面所见基岩为花岗岩、硅质岩, 事实上这两种基岩电阻率也

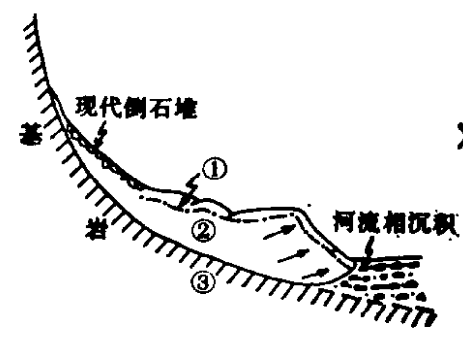

(1)话动层;

(2)冻结砂砾石层;

(B) 基岩

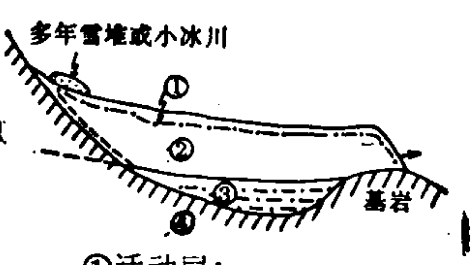

(1)话动层：

(2)东结础砾石层;

(1)末冻结沉积物层：

(1)基岩

图 3 天山型(左)与阿尔早斯山型(右,据 w. Haeberli，1985) 石冰川结构比较

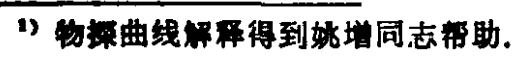


往往低于含冰冻结砂砾石); 在 $A B / 2$ 为 $160 \mathrm{~m}$ 左右, 电阻辛再次升至 3.7 万 $9 \mathrm{~m}$ 左右, 推测分 析是为基岩岩性变化所致. 根据坑探和物探资料可做出本区三层式与阿尔卑斯山四层式石冰 川结构对比图 (图 3). 可以说,我们首次发现了世界上有两种温度和结构类型的石冰川; 即前 者反映了“一冻到底”的大陆性山地冷底石冰川的特征,亦即“冷性石冰川”，后者反映了“暖底 的“海洋性“暖性石冰川”的特征.

\section{三、运 动 特 征}

我们采用大平板仪定点重复测绘、布设定位油渿基线、定位编号砾石并结合砾向组构量测 等来观测石冰川运动. 通过观测, 总结出以下若干特征.

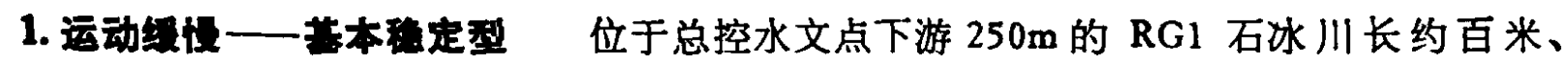
宽 60 余米, 为本区少有的舌状石冰川之一. 从目前其表面植被增多和前缘年运动速率仅为 $1 \mathrm{~cm}$ 左右的情况看, 它是逐渐趋于稳定的.

2. 较活动型 利用定位基线重复观测发现 RG2 石冰川前缘顶部的 37 块涂漆巨砾每 年运动约 $11 \mathrm{~cm}$, 利用大平板仪重复测图发现 RG3 各测点平均沿主流向前进 $75 \mathrm{~cm} / \mathrm{a}, \mathrm{RG} 4$ 为 $49 \mathrm{~cm} / \mathrm{a}, R G 5$ 为 $15.5 \mathrm{~cm} / \mathrm{a}$.

3. 印戠和堆积速率 在 RG4 前缘，我们观测了石冰川卸载量和堆积率。此石冰川 前缘坡脚为 1960 年废弃的公路路面, 原路面宽 5.5m, 现因路面上侧石冰川运动和岩屑覆盖 使路面宽仅 $4 \mathrm{~m}, 25$ 年内推移 $1.5 \mathrm{~m}$, 石冰川前缘平均每年向前推进 $6 \mathrm{~cm} .1960-1985$ 年间总 的卸载量为 $1764 \mathrm{~m}^{3}$, 平均每年钧载量为 $70.56 \mathrm{~m}^{3} / \mathrm{a}$ ，换算成单位卸载量则为 $0.47 \mathrm{~m}^{3} / \mathrm{m}^{2} / \mathrm{a}$ 。这 为公路道班的工作量提供了具体的数据.

4. 运动速率的不规则性根据掩埋公路面推算出的 RG4 平均运动速率 $6 \mathrm{~cm}$ 是可事 的. 但 1985-1986 年用大平板仪测出的流速比前 25 年快得多, 测量表明其 15 个测点在 1985-1986 年间平均前移竟达 $49 \mathrm{~cm} / \mathrm{a}$. 对石冰川来说这种不规则运动是常有的事. 如 White ${ }^{[3]}$ 根据对 Arapaho 石冰川表面涂渿砾石的观测, 发现其在 1961-1964 年间平均运动 速率为 $2 \mathrm{~cm} / \mathrm{a}, 1964-1966$ 年间却增大到 $12 \mathrm{~cm} / \mathrm{a}$ 。类似现象还出现在瑞士阿尔卑斯山等许 多地区的石冰川观测中, 这表明石冰川运动和冰川运动类似有一定的不规则性.

\section{四、运动机制的探讨}

分析发现石冰川存在层间运动的差异,主要表现在:

1. 主动运动的冻结岩同层 在活动性较强的 RG2 石冰川前缘坡可以发现其中部 $20 \mathrm{~m}$ 范围内石块运动较快, 而上下两部分石块运动较慢, 上部砾石扁平面多呈水平状镶埃在斜坡 - 内、下部砾石扁平面多呈叠瓦状分布. 至于石冰川各层间运动的差异，根据 RG2 前缘坡中段 运动快且表面有细粒岩屑出现, 以及各石冰川表面砾石有局部后退等现象, 可以推测处于活动 层以下的冻结层其蠕动速率比表层和冻结的底层要快. 也就是说, 主动运动的一方是界于表 层和冻结底层之间的冻结砂砾石层, 被动的一方是表面松散岩屑的活动层. 当中层冻结岩屑 层沿愬切面逆冲前进时, 拖拽其上松散岩屑作局部滚动、滑动, 表现为既有前进下降又有后退 抬升等复杂现象.

2. 动运动的表展及共流场形式砾向组构也反映了石水川一定的表面流场形式. 此 外，运动的石冰川表面中部的流速最快是一般规律. 作者发现: (1) RG2 石冰川表层各沉积 
部位 $A B$ 面倾向均有一个主密部, 最高密度 19-22\%，主密部倾向与各自的沉积面坡向菜本 一致. (2)从 RG3 活动层内组构看, $A$ 轴平均倾向 $284^{\circ} \mathrm{NW}$, 与石冰川主流向 $285^{\circ} \mathrm{NW}$ 很接 近. 而 $A B$ 面倾向有两处, 最大主密部 $75^{\circ} \mathrm{NE}$ 基本与石冰川主流向相反. 推测这可能是石冰 川内部受冻融蠕流作用挤压变形以及石块沿流动方向蠕动时被拖拽前进所致. (3) 从各测点 组构反映的石冰川表层流场看, 该区叶状石冰川总方向是自谷壁向外并垂直于石冰川表面等 高线方向流动的(即顺压力释放方向流动)，在前缘顶部反倾坡则有局部岩屏的逆向滚动和滑 动.

\section{考文路}

[1] 季子修,冰川冻士, 2(1980), 3: 5-6.

（2］本树德、崔之久、张振拴,水川冻土, 3(1981), 增刊: 114-118.

[3] 崔之久,科学通报, 29(1984), 13: 810-813.

14] Hacberli, W., Creep of mountain permafrost: internal structure and flow of alpipe rock glaciers, Nr. 77, Mitteilungen der Versuchsanstalı für Wasserbau, Hydrologie und Glaziologie, Zürich, 1985, 24-105.

[5] White, S. E., Arctic and Alpine Research, 3(1971), 1: 43-64. 